\title{
MộT SỐ GIẢI PHÁP CHÍNH SÁCH CÂN BẦNG CUNG CẦU LƯƠNG THỰC THỰC PHẨM TRONG THỜI KÌ COVID-19
}

\author{
Nguyễn Thị Thu Hà, Hà Thị Hồng Hạnh, Hà Minh Hằng, \\ Dương Minh Hằng, Nguyễn Thị Hằng, Nguyễn Khánh Toàn,
}

Đại học Quốc gia Hà Nội

Ngày 26 Tháng 1 năm 2022

Preprint DOI: https://osf.io/bgzpq

\section{Thực trạng}

Trong bối cảnh đại dịch COVID-19 tiếp tục diễn biến phức tạp, các nước trên thế giới đều ra sức bảo vệ nguồn lương thực thực phẩm của mình bằng các chiến lược khác nhau. Nước xuất khẩu thì điều chỉnh chính sách xuất khẩu, "găm hàng", xuất khẩu ít đi khiến nguồn cung ứng bị gián đoạn, giá cả bấp bênh, trong khi nước nhập khẩu thì cố gắng tích trữ nhiều. Nếu tình trạng kéo dài, một số nước phải đối mặt với nguy cơ an ninh lương thực bị đe dọa, thiếu hụt nguồn cung hàng hóa.

Tổ chức Nông Lương Liên Hợp Quốc (FAO) (Lê Dương, 2020) đã đưa ra cảnh báo về nguy cơ thiếu hụt lương thực trên toàn thế nếu các nước không quản lý tốt tình trạng khủng hoảng do đại dịch COVID 19 gây ra. Bên cạnh đó, FAO cũng bày tỏ sự lo lắng về việc đứt gãy chuỗi cung ứng lương thực toàn cầu và đưa ra nhận định rằng thế giới có thể phải đối mặt với cuộc khủng hoảng lương thực nếu không kịp thời triển khai các biện pháp bảo vệ những đối tượng dễ bị tổn thương và duy trì chuỗi cung ứng thực phẩm toàn cầu dưới tác động của đại dịch. Một thống kê của $\mathrm{FAO}$ cho thấy, có khoảng 820 triệu người (chiếm gần 12\% dân số) đang trong tình thế không đủ lương thực, thực phẩm để dùng hàng ngày và khoảng 113 triệu người đang phải sống trong đói nghèo và cần phải nhờ vào trợ cấp lương thực (BBT, 2020d). 
Ở Việt Nam, dịch bệnh COVID 19 diễn biến phức tạp: hạn chế di chuyển, đóng cửa hàng quán, sự phân phối nguồn hàng không đều giữa các vùng an toàn và không an toàn đã gây áp lực lên thị trường, làm đứt gãy chuỗi cung cầu (Nguyên, 2020). Ở một số tỉnh, thành phố của nước ta xảy ra tình trạng cá nhân và tổ chức đầu cơ tích trữ hàng hóa, lương thực, thực phẩm gây rối loạn thị trường, mất cân bằng giá cả gây ảnh hưởng đến nhu cầu mua hàng của người tiêu dùng. Đồng thời do sức mua tăng đột ngột, nhu cầu cao hơn nguồn cung nên có hiện tượng các hộ kinh doanh tự phát, nhỏ lẻ "hét giá" và nhiều nơi quá tải thậm chí "cháy hàng" cục bộ gây ra tình trạng thiếu hụt lương thực, thực phẩm trong thời gian ngắn. Tất cả những yếu tố đó đã gây ra hiện trạng cung - cầu mất cân đối.

Theo báo cáo gần đây của UNCTAD (Hội nghị Liên Hợp Quốc về Thương mại và Phát triển), đối với các nước phát triển, nền kinh tế thế giới giảm 3,5\% trong năm 2020. Tốc độ tăng trưởng khu vực Đông Nam Á cũng giảm 3,9\%. Việt Nam, quốc gia với mức tăng trưởng 2,9\% trong năm 2020 (Manh Hung, 2021), là một nước vượt trội trong khu vực nhờ việc kiểm soát dịch bệnh kịp thời và hiệu quả. UNCTAD dự báo sản lượng thế giới là sẽ tăng trưởng $5,3 \%$ trong năm nay khi nền kinh tế khôi phục vị thế đã mất vào năm 2020, nhưng sẽ chững lại vào năm 2022. Mặc dù tăng trưởng theo xu thế trên vẫn duy trì trong năm 2021-2022, nhưng kinh tế thế giới vào cuối năm 2022 sẽ chỉ đạt 10 nghìn tỷ USD thấp hơn nhiều so với thực tế đáng lẽ sẽ đạt được nếu không có đại dịch COVID 19. Ngoài ra, sự phục hồi của Đông Nam Á cũng sẽ bị chậm lại bởi đợt bùng phát dịch mới nhất, tăng trưởng sẽ phục hồi và bứt tốc vào năm 2022. Khối lượng thương mại quốc tế giảm 5,6\% vào năm 2020, mức giảm này ít nghiêm trọng hơn so với dự đoán. UNCTAD kỳ vọng mức tăng trưởng thực tế có thể đạt gần 10\% vào năm 2021 .

Một cuộc khảo sát của Nielsen IQ được thực hiện vào tháng 2/2020 tại Việt Nam đã chỉ ra rằng COVID 19 đã khiến cho $45 \%$ người tiêu dùng tăng cường dự trữ thực phẩm ở nhà, con số này nhiều hơn trước, $50 \%$ trong số đó giảm tần suất đến các địa điểm để mua hàng hóa (siêu thị, cửa hàng tạp hóa...) và $25 \%$ số người hạn chế các hoạt động ăn ngoài. Những mặt hàng được người Việt tích trữ nhiều nhất bao gồm mì gói $(+67 \%)$, thực phẩm đông lạnh $(+40 \%)$ và xúc xích tiệt trùng (+ 19\%) (BBT, 2021a). Các mặt hàng thiết yếu cũng có sự tăng trưởng về doanh thu do sự gia tăng trong nhu cầu của người tiêu dùng. Khảo sát của Kantar cũng đã cho thấy, việc đóng cửa trên toàn quốc vào tháng 4 năm 2020, bánh mì đóng gói và sữa hộp tại Hồ Chí Minh 
tăng lần lượt $112 \%$ và $12 \%$ so với cùng kỳ vào năm ngoái. Ngược lại, đồ uống có cồn và đồ uống có đường giảm tiêu thụ trong quý đầu tiên của năm 2020.

Ở châu Âu, nhu cầu về bánh mì tăng 76\% và rau tăng 52\% trong một tuần khi dịch bệnh được công bố (Abhijit Barman, Rubi Das, 2021), mối quan tâm đối với các mặt hàng có cồn không tăng. Theo báo cáo của Hội đồng Nghiên cứu và Kinh tế Nông nghiệp (CREA) của Ý, trong thời gian cách ly của đại dịch COVID 19, tiêu thụ sản phẩm thực phẩm tăng 29\% đối với trái cây, rau $33 \%$, các loại đậu 26,5\% và dầu ô liu 21,5\% (Abhijit Barman, Rubi Das, 2021). Ở Mỹ, 70\% khách hàng giảm tần suất mua sắm mặt hàng thực phẩm trực tiếp và ưa chuộng hình

\section{Chính sách}

COVID 19 đã và đang gây ra hàng loạt hệ lụy to lớn đối với kinh tế và xã hội. Việc cân bằng giữa tái thiết kinh tế và đảm bảo sức khỏe của người dân lúc này vẫn là lựa chọn khó khăn của chính phủ. Bởi cái chết vì đói nghèo còn đến nhanh hơn cái chết vì virus. Chính vì vậy Nhà nước ta đã đưa ra các chính sách, giải pháp tạm thời để khắc phục tình trạng trước mắt.

Đầu tiên, Chính phủ tung ra các gói cứu trợ khẩn cấp để hỗ trợ tiền mặt cho người bị thất nghiệp trong dịch bệnh. Ở Việt Nam, có 2 gói hỗ trợ lớn là "Gói hỗ trợ an sinh 62.000 tỷ VNĐ" (Thu Huong, 2020), người dân sẽ được nhận tiền mặt; và “Gói chính sách tiền tệ 300.000 tỷ VNĐ” (Anh Thu, 2021) để đảm bảo doanh nghiệp không thiếu vốn tín dụng, không phải trả nợ ngay và duy trì sản xuất.

Tiếp theo, Chính phủ tham gia vào việc thực hiện công tác điều tiết, cung ứng hàng hóa thiết yếu thông suốt tại các thành phố, tỉnh có dịch, với các địa phương khác. Chẳng hạn như Bộ Công Thương đã có đề xuất gửi thủ Tướng chính phủ (Ban biên tập, 2021) ban hành danh mục “Hàng hóa cấm lưu thông”. Bên cạnh đó cho phép các hàng hóa không nằm trong danh mục cấm được phép vận chuyển đến các tỉnh thành trong điều kiện dịch COVID 19 để có thể đáp ứng nhu cầu thiết yếu hàng ngày của người dân.

Bên cạnh đó, Chính phủ cũng chỉ đạo đến các địa phương, các bộ ngành để tháo gỡ những khó khăn, thúc đẩy sản xuất, lưu thông hàng hóa: Bộ nông nghiệp và phát triển chỉ đạo các địa phương triển khai đồng bộ dây chuyền sản xuất nhằm đảm bảo nguồn cung thực phẩm 
thiết yếu cho người tiêu dùng (Ban biên tập, 2021). Bộ công thương hướng dẫn các địa phương kiểm soát tốt dịch mở lại các chợ đầu truyền thống, chợ đầu mối, xây dựng các chợ an toàn (Ban biên tập, 2020) để kịp thời cung ứng hàng hóa, xây dựng các chợ an toàn và các quầy hàng được trang bị cơ sở hạ tầng để giảm sự lây lan của COVID 19. Bộ giao thông vận tải chỉ đạo các cơ quan liên quan bảo đảm hệ thống giao thông thông suốt trên toàn quốc, tạo điều kiện thuận lợi cho việc vận chuyển các nhu yếu phẩm thiết yếu và Bộ tài chính chỉ đạo các cơ quan hải quan (Ban biên tập, 2021) tại cửa khẩu làm thủ tục và thông quan nhanh chóng đối với các mặt hàng qua cửa khẩu, ưu tiên về thủ tục hải quan, tạo điều kiện thuận lợi cho việc thông quan... Không những thế, Chính phủ còn có những cuộc gặp mặt cấp cao với các nước trên thế giới và khu vực nhằm thảo luận và đưa ra cách khắc phục để giải quyết vấn đề nguồn cung cầu hàng hoá giữa các nước nhằm cùng hỗ trợ nhau vượt qua khó khăn và mở ra hướng đi cho ngành xuất nhập khẩu lương thực thực phẩm của nước nhà trong tình hình dịch bệnh khó khăn. Điển hình, ngày 21/10/2020, Hội nghị Bộ trưởng nông lâm nghiệp ASEAN (AMAF 42) (Ban biên tập, 2020), đại diện các nước ASEAN đã ngồi lại cùng nhau thảo luận về cách ứng phó với sự bùng phát của COVID-19 đồng thời nhất trí thông qua Khung an ninh lương thực chung của ASEAN (AIFS) và Kế hoạch hành động chiến lược về an ninh lương thực ASEAN (SPA-FC) giai đoạn 2021 - 2025 (Ban biên tập, 2020) với mục đích đảm bảo an ninh lương thực thực phẩm và dinh dưỡng lâu dài, cải thiện sinh kế của người nông dân trong khu vực ASEAN.

Ngoài ra, Chính phủ tạo điều kiện cho doanh nghiệp thông qua việc cơ cấu lại thời hạn trả nợ, miễn, giảm, hạ lãi suất cho vay đồng thời có chính sách hoãn, giãn thuế để doanh nghiệp duy trì hoạt động trong tình hình dịch COVID kéo dài. Mặt khác, Chính phủ ưu tiên tiêm vaccine đến vùng dịch, vùng có nguy cơ cao. Đối với doanh nghiệp cũng vậy, ưu tiên cho các doanh nghiệp thuộc nhóm đối tượng có nguy cơ cao như vận tải, sản xuất, giao nhận để tránh đứt gãy chuỗi cung ứng. (PGS., TS. Nguyen Anh Phong, Truong Đai học Kinh tế-Luật - ThS. Nguyễn Thị Nga Dung, 2020) (Thủ tướng Chính phủ, 2020) (ThS. Pham Thi Thanh Thanh ThS. Hoang Thi Hoa - Truong Đai hoc Thuong mai, 2020)

Và điều quan trọng cuối cùng cũng là nhân tố hàng đầu quyết định dịch bệnh có được đẩy lùi không đó chính là nâng cao nhận thức của cộng đồng về COVID 19 và cách ngăn chặn sự lây lan của nó. Qua các phương tiện truyền thông và các kênh tin tức chính thức của Chính phủ như VTV, thông tin về dịch bệnh và những khuyến cáo của Bộ y tế được tiếp cận gần hơn với người 
dân, kịp thời giải đáp mọi thắc mắc và trăn trở từ đó nâng cao nhận thức cộng đồng để mọi người cùng chung sức đẩy lùi dịch bệnh.

\section{Thảo luận}

\section{1. Ý nghĩa của thông tin}

Nghiên cứu và phân tích nguồn cung lương thực, thực phẩm cũng như những tác động của dịch COVID 19 lên nó sẽ giúp chúng ta có cái nhìn tổng quát nhất về những ảnh hưởng của COVID lên thị trường trong nước và đưa ra đánh giá về khả năng phục hồi của nền kinh tế trong tương lai từ đó có những chính sách ứng phó, điều chỉnh kịp thời, phù hợp với tình hình hiện tại để đưa nền kinh tế thoát khỏi khó khăn và đáp ứng nhu cầu lương thực, thực phẩm của người tiêu dùng.

\subsection{Thuận lợi}

Thứ nhất, theo nghiên cứu, khi đại dịch bùng phát, mọi người có xu hướng tuân theo một chế độ ăn uống lành mạnh hơn để bảo vệ bản thân và nâng cao hệ thống miễn dịch của họ (Rodríguez-Pérez et al., 2020). Do đó, nhu cầu về thực phẩm chức năng có chứa hoạt chất sinh học hay các nhóm thực phẩm bổ sung vitamin như hoa quả và một số loại rau củ tăng cao. Trong một cuộc điều tra yêu cầu cung cấp thông tin ở các quốc gia châu Âu về COVID 19 (Abhijit Barman, Rubi Das, 2021) nhu cầu tiêu thụ bánh mì đã tăng 76\% và rau củ tăng 52\% trong một tuần khi dịch bệnh được công bố. Các báo cáo khảo sát cũng cho thấy, $50 \%$ khách hàng đã chi tiêu nhiều hơn cho các thực phẩm tăng cường sức đề kháng và hệ miễn dịch, các thực phẩm có nguồn gốc tự nhiên, thực phẩm sạch và lành mạnh. Theo đó, các doanh nghiệp cũng phải có những điều chỉnh hiệu suất hoạt động cho phù hợp.

Thư hai, an toàn thực phẩm đã được quan tâm nhiều hơn để ngăn chặn sự lây truyền của coronavirus giữa các nhà sản xuất, nhà bán lẻ và người tiêu dùng, điều này đồng nghĩa với với nâng cao chất lượng nguồn cung thực phẩm. Đại dịch COVID 19 đảm bảo việc sử dụng các hệ thống dành cho khủng hoảng và ảnh hưởng đến các trao đổi ràng buộc về mặt pháp lý trong chuỗi cung ứng thực phẩm. Đồng thời, nó dẫn đến những điều chỉnh trong nguồn cung cấp-yêu cầu bình đẳng hóa và các doanh nhân và nông dân gặp khó khăn (Abhijit Barman, Rubi Das, 2021). Do 
thiệt hại kinh tế và việc phân bổ tài sản của họ tập trung vào động lực kinh tế và các chương trình trợ giúp công cộng, chính phủ các nước đang phải đối mặt với áp lực tài chính. Có thể hình dung rằng việc không đủ tài chính có thể làm giảm nhu cầu đối với các sản phẩm và năng suất nông nghiệp. Nhu cầu giảm sẽ đặc biệt là khu vực tư nhân đang gia tăng ở các nước đang phát triển.

\subsection{Khó khăn}

Tình hình dịch COVID 19 gây thêm lo ngại cho các thị trường quốc tế. Theo trang SeafoodSource ngày 01/09/2021, các lãnh đạo ngành hải sản của Việt Nam cũng đang phải lo ngại ngày càng nhiều hơn về tác động của dịch COVID 19 tới nguồn cung thuỷ hải sản. Lý do cho việc này là trong số hơn 390.000 người bị nhiễm virus corona từ ngày 27/04, hầu hết là sống ở miền nam, khu vực tập trung nhiều cơ sở nuôi trồng thủy sản. Các biện pháp an toàn dịch tễ, giãn cách xã hội ở hàng chục tỉnh thành, cũng như việc các cơ sở chế biến thủy sảnđã khiếncác hoạt động bị hạn chế, làm cho sản lượng thủy sản của Việt Nam giảm mạnh. Nay các doanh nghiệp trong ngành đang rất quan ngại về những khó khăn trong hoạt động nuôi trồng thủy sản, cũng như sự không ổn định về nhu cầu của người tiêu dùng và cả về khả năng xuất khẩu có thể sẽ ảnh hưởng nghiêm trọng đến mùa thu hoạch tôm thứ hai trong năm. (Thanh Phuong, 2021)

Trên thế giới, nhiều lao động có tay nghề cao trong lĩnh vực nông nghiệp không thể đưa sản phẩm đến với người tiêu dùng ở các quốc gia khác nhau do chính sách đóng cửa biên giới. Sự thiếu hụt lực lượng lao động và giãn cách xã hội đã có ảnh hưởng vô cùng lớn tới quá trình sản xuất lương thực, gây ra cuộc khủng hoảng làm suy giảm nguồn cung từ các trang trại và doanh nghiệp nông nghiệp, làm chậm quá trình cung cấp thực phẩm trên quy mô toàn cầu, đặc biệt với những nước ít phát triển nông nghiệp (Serpil Aday, 2020). Việc đóng cửa các cửa hàng thực phẩm cũng gây ảnh hưởng ngày càng lớn trong chuỗi cung ứng thực phẩm. Các nhà sản xuất buộc phải tách đàn gia súc ra vì họ không có nguồn tiêu thụ. Nhu cầu của khách hàng cao hơn dẫn đến các kệ hàng trống, và nguồn cung giảm khiến giá các mặt hàng thịt tăng lên. (Imran Ghori, 2020) 


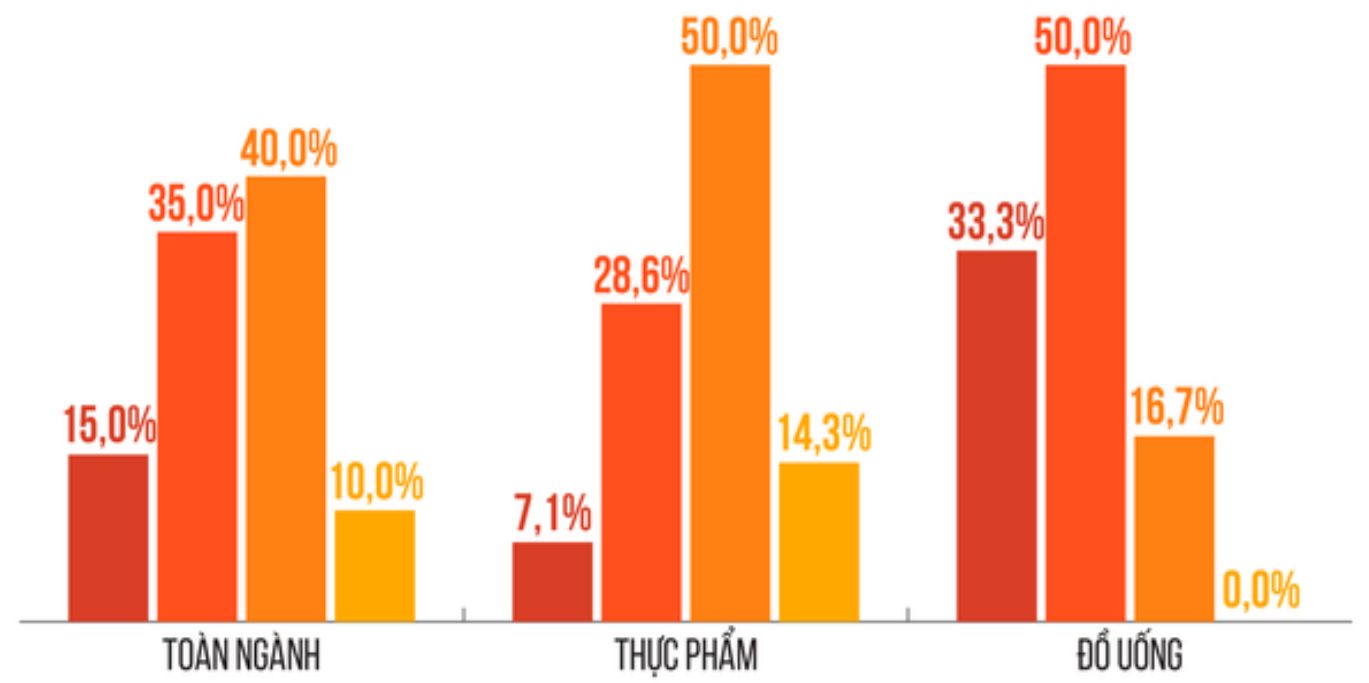

Tác động nghiêm trọng

Tác động itt, không đáng kế
Tác động nghiêm trọng vừa phải

Không chịu tác động

Ảnh 2: Kết quả khảo sát về mức độ ảnh hưởng của COVID 19 tới một số doanh nghiệp ngành thực phẩm

https://vnn-imgs-f.vgcloud.vn/2020/09/23/11/tcbc-top-10-f-b-2020-hinh-1.png

\subsection{Cơ hội}

Việt Nam có nhiều Hiệp định thương mại tự do FTA, đây là cơ hội để chúng ta tìm kiếm, đa dạng hóa thị trường liên quan đến thương mại, du lịch, đầu tư, logistic. Ví dụ: Đối với xuất khẩu nông sản, do yêu cầu cao từ phía Trung Quốc nên nước ta đã nâng cao tiêu chuẩn chất lượng hàng hóa nông sản. Đây là tín hiệu tốt đối với xuất khẩu sang Trung Quốc trong dài hạn và tạo cơ hội để nước ta chinh phục và tìm kiếm nhiều thị trường khó tính hơn.

Với xu thế hiện nay, người tiêu dùng có yêu cầu ngày càng cao về chất lượng hàng hóa, cách mạng tiêu dùng xanh hơn (Thu Hang, 2020). Để hạn chế những tác động của dịch bệnh, làm việc online, mua bán online, học online được ưu tiên. Do đó tạo cơ hội cho nước ta phát triển lĩnh vực chuyển đổi số. Với việc nới lỏng giãn cách, cùng với nhu cầu mặt hàng gạo trên thế giới ngày càng tăng cao được nhận định sẽ mở ra cơ hội lớn cho các doanh nghiệp trong lĩnh vực xuất khẩu gạo của Việt Nam. (Kovacevic, Rialda; Mwencha, Marasi; Ouma, Ahmed; Adeyeye, Moji Christianah; Folorunso, 2021) 


\subsection{Thách thức}

Theo báo cáo gần nhất của Chương trình phát triển Liên hợp quốc (UNDP) ngày 27/9 thì đại dịch COVID-19 là cuộc khủng hoảng sức khỏe cực kì tồi tệ mà hệ lụy của nó là nỗi khổđau và thiệt hại lớn nhất đó là mạng sống con người. Đại dịch COVID 19, cũng là thách thức nghiêm trọng nhất cho nền kinh tế, thậm chí nó còn ảnh hưởng to lớn và sâu rộng hơn cả cuộc Khủng hoảng Tài chính Toàn cầu năm 2008-2009 (Manh Hung, 2021). Dịch bệnh kéo dài với nhiều đợt bùng phát khiến tốc độ tăng trưởng kinh tế, giao thương, mở cửa của các quốc gia chậm lại. (Bach Xuan Tran, Hien Thi Nguyen, Huong Thi Le, Carl A. Latkin, Hai Quang Pham, Linh Gia Vu, Xuan Thi Thanh Le, Thao Thanh Nguyen, Quan Thi Pham, Nhung Thi Kim Ta, Quynh Thi Nguyen, Cyrus SH Ho, 2020)

\subsection{Chiều hướng}

Dịch COVID 19 trên cả nước vẫn diễn biến phức tạp, do đó tình hình thị trường, cung cầu, giá cả có những biến động nhất định. Trong thời gian tới, việc tập trung theo dõi sát diễn biến giá cả, cung cầu hàng hóa là việc cấp thiết để kịp thời tham mưu, đề xuất cho Chính phủ các giải pháp bình ổn giá cả thị trường, cung cấp đầy đủ hàng hóa thiết yếu phục vụ nhu cầu người dân. Bên cạnh đó chính phủ, các cơ quan tổ, chức doanh nghiệp và cá nhân sẽ phải có những thay đổi để thích nghi với tình hình hiện tại bằng cách cập nhập nhiều xu thế kinh doanh mới, áp dụng nhiều công nghệ hiện đại của thương mại điện tử vào việc bán buôn để có thể duy trì và phát triển trong tình hình dịch bệnh phức tạp. (Karine Szegedi, 2020) (Adam Smith, 2020)

\section{7. Ý nghĩa của sự thay đổi nguồn cung do đại dịch COVID-19}

Bên cạnh những thách thức mà nền kinh tế phải đối mặt do sự thay đổi nguồn cung lương thực, thực phẩm thì nó cũng mang đến nhiều ý nghĩa thiết thực. Những khó khăn trong việc cung ứng hàng hoá ra thị trường, việc ngưng trệ của xuất khẩu, lưu thông hàng hoá và tâm lý sợ dịch của người dân đòi hỏi phải có những biện pháp mới thay thế những cách thức truyền thống để thích nghi với thị trường.

Chính phủ đã làm việc nhanh chóng hơn, thay đổi chính sách liên tục đưa ra những giải pháp kịp thời để vực dậy nền kinh tế vượt qua khó khăn cũng như đảm bảo nhu cầu lương thực, 
thực phẩm của người dân. Điều đó điều hỏi các cơ quan cấp dưới phải linh hoạt điều chỉnh kế hoạch để giúp địa phương vượt qua dịch bệnh (giải cứu nông sản: thanh long, dưa hấu..)

Các doanh nghiệp đã tìm ra cách điều hành mới, thay đổi quy trình sản xuất truyền thống, chú trọng, quan tâm hơn đến người lao động như chính sách tiêm vaccine, lập khu cách ly kết hợp sản xuất cho công nhân để không bị đứt gãy chuỗi sản xuất.

Các cá nhân, tiểu thương cũng đã có những thay đổi thích hợp với điều kiện, tiếp cận ngày càng gần hơn với công nghệ, thông tin, nâng cao trình độ, sự sáng tạo trong cách thức buôn bán, sản xuất để không bị đại dịch kìm hãm việc kinh doanh (bán hàng online, siêu thị 0đồng, điểm bán hàng lưu động, làm bún dưa hấu, bánh mì thanh long...). (Cristián Sagal, 2020)

\section{4.Đề xuất giải pháp khắc phục}

\subsection{Cách tiếp cận chung}

Để đi tìm giải pháp cho vấn đề nêu trên cách tiếp cận chung là sử dụng (áp dụng) hệ xử lý thông tin 3D (Khuc, 2022; Vuong, Q.H., 2022). Về cơ bản đây là hệ giải pháp sáng tạo được áp dụng cho nhiều vấn đề từ nhỏ đến lớn. Hệ này gồm có 3 cách thức bao gồm: chuyên gia, hợp tác, và thực thi kỷ luật. Tuy nhiên biện pháp truyền thông được coi là giải pháp rất quan trọng vì liên quan đến thông tin đầu vào cho quá trình nấu luyện và xử lý để tìm ra các giải pháp hiệu quả. Ở D thứ nhất, các chuyên gia am hiểu trong lĩnh vực cụ thể (cung cầu lương thực thực phẩm) sẽ đưa ra những tư vấn (giải pháp) phù hợp. Ở $\mathrm{D}$ thứ hai là sự hợp tác giữa các bên liên quan gồm có nhà nước, doanh nghiệp, chuyên gia, người tiêu dùng để có thông tin thông suốt liên quan. $\mathrm{D}$ thứ ba là tiếp tục duy trì thực thi chính sách kinh tế vĩ mô (cung cầu) và các quy định liên quan với sự giám sát chặt chẽ của các bên nhằm đạt hiệu quả. $\mathrm{Ba} \mathrm{D}$ này được thực hiện đồng thời và không tách rời nhau cho đến khi có được giải pháp tốt nhất được tìm ra (Vuong \& Napier, 2014). 


\subsection{Giải pháp cụ thể}

\section{*Phía nhà nước}

Ngoài những giải pháp ngắn hạn mà nhà nước đã thực hiện để ứng phó với COVID 19, Chính phủ cũng cần thực hiện các chính pháp mang tính dài hạn để chuẩn bị những điều kiện cơ bản nhất cho công cuộc phát triển bền vững sau đại dịch và ổn định thị trường.

Một là, đổi mới mô hình tăng trưởng theo hướng dựa vào công nghệ- đổi mới sáng tạo, có tư duy không ngại thất bại và chấp nhận rủi ro, ngoài ra cần khuyến khích khởi nghiệp.

Hai là, nhà nước cần tiếp tục thực hiện các chính sách hỗ trợ doanh nghiệp theo hướng tập trung hơn, đúng đối tượng và thực chất hơn, theo sát với nhu cầu của doanh nghiệp. Bên cạnh đó, cần phải đưa ra sự chọn lọc, phân loại ngành nghề với mục đích hỗ trợ, trên cơ sở đánh giá, khảo sát nhanh tác động của dịch COVID-19 đối với hoạt động của các ngành, nghề cụ thể. Ngoài ra, cần cho phép kéo dài thời gian giãn thuế, hoãn thuế, tiền thuê đất và bổ sung thêm đối tượng cần được gia hạn để doanh nghiệp phần nào vơi bớt khó khăn về thanh toán chi phí.

Ba là, hoàn thiện thể chế, xây dựng nhà nước kiến tạo,phát triển, liêm chính và hành động thông qua cân bằng quyền lực trong bộ máy nhà nước, tôn trọng và bảo vệ quyền bình đẳng giữa các thành phần kinh tế,thực hiện phân cấp quản lý với phân cấp ngân sách, tinh giản và kiện toàn bộ máy nhà nước.

Bốn là, Chính phủ, cơ quan và các nhà lãnh đạo phải xác định thời điểm và phương pháp thích hợp để thực hiện cùng lúc nhiều nhiệm vụ phức tạp như đưa lực lượng lao động quay trở lại nơi làm việc sau khi các lệnh cấm được nới lỏng, vừa duy trì sản xuất nhưng vẫn phải đảm bảo an toàn phòng dịch. (BBT, 2020b)

Ngoài $r a$, vừa tập trung chống dịch nhưng vẫn phải đảm nền kinh tế bằng việc nhanh chóng phân phối vaccine cho các tỉnh thành phố trên cả nước để người dân yên tâm lao động. 


\section{*Phía cá nhân và doanh nghiệp.}

Thư nhất, thực hiện nghiêm các chỉ thị, quy định của nhà nước. Bên cạnh đó cần nắm bắt thông tin kịp thời về chính sách nhà nước, cũng như tình hình dịch bệnh ở các quốc gia nhằm tránh việc bị động trong nguồn cung hàng hóa và có thể đưa ra giải pháp khắc phục nhanh chóng.

Thư hai, doanh nghiệp cần chủ động hơn trong việc đổi mới tư duy, cách thức sản xuất, tìm ra hướng đi mới, biết nắm bắt thời cơ : đầu tư vào công nghệ tiên tiến, đồng bộ hóa mô hình sản xuất nhằm đáp ứng được nhu cầu của thị trường trong bối cảnh hội nhập quốc tế.

Thư $b a$, để tránh tình trạng đứt gãy chuỗi cung ứng do tình hình dịch bệnh diễn biến phức tạp,doanh nghiệp cần chủ động tìm nhiều nguồn cung ứng khác nhau để đa dạng hóa sản phẩm đồng thời giảm phụ thuộc vào các doanh nghiệp cũng như các yếu tố khách quan bên ngoài.

Thứ tux, cuộc Cách mạng công nghiệp 4.0 sẽ tạo ra sự cạnh tranh ngày càng gay gắt giữa các doanh nghiệp, giữa các nền kinh tế; và người lao động sẽ trở thành nhân tố quyết định. Vậy nên doanh nghiệp cần quan tâm, chú trọng vào việc đầu tư và phát triển nguồn nhân lực.

Cuối cùng, bản thân người lao động cũng cần trang bị yếu tố, kỹ năng để thích ứng hoàn cảnh dịch bệnh phức tạp, tránh tình trạng tích trữ, đầu cơ trục lợi. (FAO, 2020)

\section{Kết luận}

Trong giai đoạn tới, dịch bệnh vẫn chưa có dấu hiệu đã được kiểm soát hoàn toàn, vấn đề nguồn cung cầu lương thực thực phẩm nếu không được giải quyết triệt để sẽ gây ra những hậu quả khôn lường. Điều này có thể thấy rõ dựa trên các số liệu cụ thể mà bài tiểu luận trên đề cập đến. Qua bài tiểu luận, cả nhóm mong rằng có thể đưa ra cái nhìn tổng quát về các khía cạnh khác nhau của vấn đề đến mọi người. Tuy nhiên, do dung lượng có hạn, những ý kiến mà nhóm đưa ra chỉ mang tính chất đề xuất, tham khảo, chưa thể toàn diện mọi mặt và vẫn cần nghiên cứu bổ sung thêm.

\section{Tài liệu tham khảo}

Abhijit Barman, Rubi Das, P. K. De. (2021). Impact of COVID-19 in food supply chain: Disruptions and recovery strategy. Mathematics, National Institute of Technology Silchar, Silchar, Assam 788010, India. https://www.sciencedirect.com/science/article/pii/S2666518221000048 
xác, đơn giản thủ tục để người lao động sớm được thụ hưởng. Báo Lao Động. https://laodong.vn/cong-doan/goi-ho-tro-30000-ti-dong-tu-quy-bao-hiem-that-nghiepnhanh-chinh-xac-don-gian-thu-tuc-de-nguoi-lao-dong-som-duoc-thu-huong-957679.ldo

Bach Xuan Tran, Hien Thi Nguyen, Huong Thi Le, Carl A. Latkin, Hai Quang Pham, Linh Gia Vu, Xuan Thi Thanh Le, Thao Thanh Nguyen, Quan Thi Pham, Nhung Thi Kim Ta, Quynh Thi Nguyen, Cyrus SH Ho, R. C. H. (2020). Tác động của COVID-19 đối với kinh tế tốt và chất lượng cuộc sống của người Việt Nam trong thời kỳ quốc gia xã hội xa cách. $P M C$. https://www.frontiersin.org/articles/10.3389/fpsyg.2020.565153/full

BBT. (2020a). COVID-19 và chuỗi cung ứng thực phẩm: Khôi phục thị trường ở Mutare. UNDP in Zimbabwe.

https://www.Zw.undp.org/content/zimbabwe/en/home/presscenter/articles/covid19-and-thefood-supply-chain--restoring-markets-in-mutare-

.html?utm_source=EN\&utm_medium=GSR\&utm_content=US_UNDP_PaidSearch_Brand English\&utm_campaign $=$ CENTRAL\&c_src=CENTRAL\&c_src2=

BBT. (2020b). Đánh giá các chính sách ứng phó với COVID-19 và các khuyến nghị. Đại Học Kinh Tế Quốc Dân.

https://www.jica.go.jp/vietnam/vietnamese/office/topics/c8h0vm00009crmm6att/210305_01_vn.pdf

BBT. (2020c). Đối tác phát triển nông nghiệp bền vững ở Việt Nam PSAV. PSAV. http://psavmard.org.vn/virtual-42th-meeing-of-asean-ministers-on-agriculture-and-forestry-(amaf42).html

BBT. (2020d). Thế giới canh cánh nỗi lo khủng hoảng lương thực vì đại dịch COVID-19. In Đài phát thanh và truyền hình Ninh Bình. https://nbtv.vn/news/4/4174/the-gioi-canh-canh-noilo-khung-hoang-luong-thuc-vi-dai-dich-covid-19

BBT. (2021a). Tác động của COVID-19 đến ngành thực phẩm và đồ uống. Innovative Hub Viet Nam. https://innovativehub.com.vn/tac-dong-cua-covid-19-den-nganh-thuc-pham-va-douong-fb/

BBT. (2021b). Thủ tướng Chính phủ chỉ đạo thúc đẩy sản xuất, lưu thông, xuất khẩu nông sản. In Báo Chính phủ. https://moit.gov.vn/tin-tuc/hoat-dong/thu-tuong-chinh-phu-chi-dao-thucday-san-xuat-luu-thong-xuat-khau-nongsan.html?fbclid=IwAR3FM0G93Qc9A_c5k_YEutbhO16_kJSFFP4E9-ixH3IO71GOfbnir3NVg

Cristián Sagal. (2020). Opportunities in the food sector in the midst of the COVID-19 crisis. Invest Chile. http://blog.investchile.gob.cl/opportunities-in-the-food-sector-in-the-midst-ofthe-covid-19-crisis

FAO. (2020). COVID-19 and the risk to food supply chains: How to respond? In FAO. https://www.fao.org/documents/card/en/c/ca8388en/

Imran Ghori. (2020). How COVID-19 is affecting the global supply chain. University of California, Riverside. https://news.ucr.edu/articles/2020/04/29/how-covid-19-affectingglobal-supply-chain

Khuc, Q. Van. (2022). Về khả năng ứng dụng của hệ xử lý thông tin 3D và nguyên lý bán dẫn giá trị trong tìm kiếm giải pháp cho vấn đề ô nhiễm môi trường và biến đổi khí hậu ở Việt Nam. Tạp Chí Kinh Tế và Dư Báo, 1-5. https://kinhtevadubao.vn/ve-kha-nang-ung-dungcua-he-xu-ly-thong-tin-3d-va-nguyen-ly-ban-dan-gia-tri-trong-tim-kiem-giai-phap-cho-vande-o-nhiem-moi-truong-va-bien-doi-khi-hau-o-viet-nam-20840.html

Kovacevic, Rialda; Mwencha, Marasi; Ouma, Ahmed; Adeyeye, Moji Christianah; Folorunso, O. 
(2021). Challenges and opportunities of supply chain in time of COVID-19. Worldbank. Lê Dương. (2020). FAO: Thế giới cần hành động để không khủng hoảng lương thực vì COVID19. Báo Bnews.

Manh Hung. (2021). Đại dịch Covid-19 thách thức kinh tế nghiêm trọng với toàn cầu. Báo Điện Tử - Đảng Cộng Sản Việt Nam. https://dangcongsan.vn/phong-chong-dich-covid-19/undpdai-dich-covid-19-thach-thuc-kinh-te-nghiem-trong-voi-toan-cau-592159.html

Nguyên, A. (2020). Tăng sức cạnh tranh của hàng Việt trong bối cảnh mới. Báo Điện Tứ - Đảng Cộng Sản Việt Nam. https://dangcongsan.vn/kinh-te-va-hoi-nhap/tang-suc-canh-tranh-cuahang-viet-trong-boi-canh-moi-567253.html

PGS., TS. Nguyen Anh Phong, Truong Đai học Kinh tế-Luật - ThS. Nguyễn Thị Nga Dung, T. Đ. học T. chính-M. (2020). Chính sách tài chính cho phục 76 hồi và phát triển kinh tế Việt Nam sau đại dịch COVID-19. Tạp Chí Tài Chính. https://tapchitaichinh.vn/su-kien-noibat/chinh-sach-tai-chinh-cho-phuc-hoi-va-phat-trien-kinh-te-viet-nam-sau-dai-dichcovid19-328466.html

Serpil Aday, M. S. A. (2020). Tác động của COVID-19 đối với chuỗi cung ứng thực phẩm. In Biga, Canakkale Onsekiz Mart University, Biga, Canakkale, Turkey. https://academic.oup.com/fqs/article/4/4/167/5896496

Thanh Phuong. (2021). Tác động của đợt dịch COVID mới lên nền kinh tế Việt Nam. Đài Phát Thanh Quốc Tế Pháp - RFI. https://www.rfi.fr/vi/tạp-chí/tạp-chí-việt-nam/20210906-tácđộng-của-đợt-dịch-covid-mới-lên-nền-kinh-tế-việt-nam.

ThS. Pham Thi Thanh Thanh ThS. Hoang Thi Hoa - Truong Đai hoc Thuong mai. (2020). Chính sách hỗ trợ doanh nghiệp bị ảnh hưởng do dịch COVID-19 và một số khuyến nghị. Tạp Chí Tài Chính. https://tapchitaichinh.vn/tai-chinh-kinh-doanh/chinh-sach-ho-tro-doanh-nghiepbi-anh-huong-do-dich-covid19-va-mot-so-khuyen-nghi-328425.html

Thu Hang. (2020). Tác động của dịch COVID-19 đối với nền kinh tế: Trong thách thức có cơ hội. Báo Điện Tử Công Thưong. https://congthuong.vn/tac-dong-cua-dich-covid-19-doi-voinen-kinh-te-trong-thach-thuc-co-co-hoi-132710.html

Thu Huong. (2020). Những trường hợp được nhận tiền từ gói hỗ trợ 62.000 tỷ đồng. Cổng Thông Tin Điện Tứ Tỉnh Phú Tho. https://phutho.gov.vn/vi/node/26054

Thủ tướng Chính phủ. (2020). Thủ tướng Chính phủ (2020), Quyết định 15/2020/QĐ-Ttg ngày 24/4/2020 về thực hiện các chính sách hỗ trợ người dân gặp khó khăn do đại dịch COVID19. In Cổng thông tin điện tư chính phủ nước CHXHCN Việt Nam.

http://vanban.chinhphu.vn/portal/page/portal/chinhphu/hethongvanban?class_id=1\&_page= $1 \&$ mode=detail\&document_id=199898

Vuong, Q. H., et al. (2022). Covid-19 vaccines production and societal immunization under the serendipity-mindsponge-3D knowledge management theory and conceptual framework. Humanities and Social Sciences Communications, 9, 22. Retrieved from: https://www.nature.com/articles/s41599-022-01034-6

Vuong, Q. H., \& Napier, N. K. (2014). Making creativity: the value of multiple filters in the innovation process. International Journal of Transitions and Innovation Systems, 3(4), 294 327. https://doi.org/10.1504/ijtis.2014.068306 